\title{
Strigolactones and gibberellic acid regulate aphid fecundity in pea
}

\author{
Hendrik Swiegers ${ }^{1}$, Barbara Karpinska ${ }^{2}$, Yan $\mathrm{Hu}^{3}$, Ian Dodd ${ }^{4}$, Anna-Maria Botha ${ }^{5}$, and \\ Christine Foyer ${ }^{2}$ \\ ${ }^{1}$ University of Birmingham Edgbaston Campus \\ ${ }^{2}$ University of Birmingham \\ ${ }^{3}$ Zhejiang University \\ ${ }^{4}$ University of Lancaster \\ ${ }^{5}$ Affiliation not available
}

August 23, 2020

\begin{abstract}
Atmospheric CO2 levels influences plant growth and susceptibility to pathogens and pests but there is little information on the mechanisms involved. We therefore studied how elevated atmospheric $\mathrm{CO} 2$ concentrations (eCO2) effects shoot branching and the performance of the pea aphid on wild type peas and on mutants that are defective in either strigolactone (SL) synthesis or signalling. Shoot branching and dry biomass accumulation were increased under eCO2 conditions in all lines. However, eCO2 decreased shoot water content only in the wild type peas but not in the SL mutants. Growth under eCO2 decreased the levels of salicylic acid and increased jasmonic acid in the wild type peas, without any significant effect on aphid fecundity. However, aphid numbers were increased on the SL mutants under both ambient and eCO2 conditions. Of the shoot phytohormones measured in this study, only gibberellic acid (GA3) was decreased in the SL mutants, an effect that was exacerbated by eCO2. There was a negative correlation between aphid fecundity and shoot GA3 levels. Taken together, these studies provide confirm that eCO2 modifies the levels of defence hormones and provides the first evidence that SL and GA3 are important regulators of plant responses to phloem-feeding insects.
\end{abstract}

\section{Introduction}

Aphids are important plant pests that often have a broad host range. In addition, they significantly reduce the yields of susceptible plants via nutrient depletion and feeding damage to host tissues and the spread of viruses (Smith and Chuang 2014). Aphids are phloem feeders, with a probing stylet that can damage as the insect searches for the phloem. In addition, the stylet secretes saliva that contains elicitors and proteins that modulate plant defensive responses (Kaloshian and Walling 2016). Nevertheless, aphid feeding triggers the host multi-level immune system that operates to mitigate the adverse effects of pathogens and insects (Zust and Agrawal 2016). The host defensive networks that underpin plant responses to aphids have been characterised in a number of plant species (Nguyen et al. 2016; Kiani and Szczepaniec 2018, Sanchez-Arcos et al. 2019; Koch et al., 2020). Aphid feeding results in extensive changes to the leaf transcriptome and metabolome signatures (Foyer et al., 2015), revealing a complex interplay between the different hormones regulating plant basal immunity. Changes in the levels of phytohormones such as jasmonic acid (JA), salicylic acid (SA), abscisic acid (ABA) and indole acetic acid (IAA) have been documented (Kerchev et al., 2013; Foyer et al., 2015). However, little attention has been paid to the role of strigolactones (SL) in plant-aphid interactions. SLs fulfil many important roles in the control of plant growth and architecture, seed dormancy and senescence, as well as abiotic stress tolerance (Al-Babili \& Bouwmeester, 2015; Waterset al ., 2017; Machin \& Bennett 2020). These carotenoid-derived phytohormones are also critical regulators of plantmicrobe interactions in the rhizosphere, such as the symbiosis with arbuscular mycorrhizal fungi (Aliche et 
al., 2020). They also serve functions in plant responses to biotic stresses to bacterial and fungal pathogens (Torres-Vera et al. 2014; Stes et al., 2015; Marzec, 2016).

Climate change is an important global challenge that will have important impacts on insects as well as their host plants. The failure to curb fossil fuel $\mathrm{CO}_{2}$ emissions, together with the inadequacy of planned mitigation measures required to achieve the United Nations Framework Convention on Climate Change Paris Agreement targets for limiting global warming, has led to strategies for carbon dioxide removal from the atmosphere (Beerling et al. 2020). The global average $\mathrm{CO}_{2}$ level is about $420 \mathrm{~mol} \mathrm{~mol}^{-1}$ and it is predicted to reach 730-1000 $\mathrm{mol} \mathrm{mol}^{-1}$ towards the end of this century (IPCC, 2014). Plant pathogens are responsible for about $25 \%$ crop losses globally in agricultural ecosystems. Crop losses due to insect herbivores are also significant particularly in African countries (Botha et al., 2019). These losses are predicted to be even higher in some crops in the future as a result of climate change and this will have serious implications for food security (Martinelli et al. , 2015). While a better understanding of the molecular events that determine how elevated $\mathrm{CO}_{2}\left(\mathrm{eCO}_{2}\right)$ influences plant-insect interactions is essential for the improvement of plant resilience traits, it is difficult to predict how this change will affect phloem feeding insects such as aphids (Sun and Ge, 2011).

The effects of high $\mathrm{CO}_{2}$ on aphid fecundity reported in literature are highly variable (Guo et al., 2014; Ryalls, et al., 2017). High atmospheric $\mathrm{CO}_{2}$ had little impact on aphid performance in oilseed rape (Himanen et al., 2008), while the performance of the pea aphid (Acyrthosiphon pisum ) was increased under $\mathrm{eCO}_{2}$ on Medicago sativa (Ryalls, et al., 2017). Growth under $\mathrm{eCO}_{2}$ increased the resistance of two $M$. truncatula genotypes to pea aphids by increasing SA-dependent defences and decreasing JA and ethylene-dependent signalling pathways, as well as increasing the density of non-glandular and glandular trichomes (Guo et al., 2014). In contrast, the performance of the pea aphid was decreased in a free air enrichment (FACE) studies of performance on Vicia faba (Mondor et al., 2005). Since photosynthesis is stimulated by high $\mathrm{CO}_{2}$ it could be predicted that assimilate transport through the phloem would be increased, benefitting phloem feeding aphids. However, aphid fecundity might be decreased by growth under elevated atmospheric $\mathrm{CO}_{2}$ because these activate SA-mediated defence pathways (Mhamdi and Noctor, 2016). Moreover, plants may perceive high $\mathrm{CO}_{2}$ as a stress, not least because growth under high $\mathrm{CO}_{2}$ alters the balance of cellular redox signalling (Foyer and Noctor, 2020).

The silencing of SL biosynthesis genes compromised plant defences against the root knot nematode (RKN) Meloidogyne incognita (Xu et al., 2019). JA and ABA, which are positive and negative regulators of RKN resistance, were both suppressed by SL in nematode-infected roots (Xu et al., 2019). However, there have been no reports of whether SLs mediate plant defences against insects or how SL signalling contributes to plant responses to high atmospheric $\mathrm{CO}_{2}$ levels. However, SLs were recently found to play a role in the stomatal closure induced by pathogens and high $\mathrm{CO}_{2}$ concentrations (Kalliola et al., 2020). These authors reported that the SL biosynthesis $(\max 3$ and $\max 4)$ and the SL perception (max2 and dwarf14 ) Arabidopsis mutants were more sensitive to infection by the biotrophic pathogen Pseudomonas syringae DC3000. Moreover, stomatal conductance was higher in the SL mutants and the stomatal responses to high $\mathrm{CO}_{2}$ were impaired in the SL biosynthesis and perception mutants (Kalliola et al., 2020).

In this study, we firstly compared the phenotypes of wild type peas and different pea ramosus mutants (rms; Johnson et al ., 2006) to growth under high atmospheric $\mathrm{CO}_{2}$ levels. Shoot architecture was compared in wild type peas and mutants that are deficient in either SL synthesis (rms1-2 and rms5-3) or SL signalling ( $r m s 3-1$ and rms4-1 ). We next compared aphid fecundity on the different lines grown under high $\mathrm{CO}_{2}$ conditions to test the hypothesis that SL-dependent pathways are important in plant defences against aphids. The results of these studies show that aphid numbers are greater on SL mutants than the wild type under both growth conditions and this is related to decreased levels of gibberellic acid.

Taken together, these data demonstrate that while SL had little effect on plant acclimation to high $\left[\mathrm{CO}_{2}\right]$, in terms of dry biomass accumulation, they apparently affect shoot water status. The role of SL in the resistance of peas to aphid infestation is perhaps not surprising given that these phytohormone have important functions in plant interactions with bacteria, fungi and nematodes. The identification of SL as a key player in plant 
defences against aphids paves the way for new strategies for the development of more aphid resistant crops.

\section{Materials and Methods}

\section{Biological resources}

Seeds of wild type peas (L107, Torsdag cultivar) and mutants deficient in either SL synthesis mutants (rms12 and rms5-3) or SL signalling (rms3-1 and rms4-1 ) seed were kindly donated by Professor Christine Beveridge. Stocks of the aphid Acyrthosiphon pisum was maintained on wild type pea at a $16 \mathrm{~h}$ day length and $22 \pm 3^{\circ} \mathrm{C}$.

\section{Growth conditions and phenotypic analysis}

Seeds of the wild type, rms3-1, rms4-1, rms1-2 andrms5-3 pea mutants were allowed to germinate in vermiculite for 5 days. Thereafter six seedlings of each genotype were transferred to Levington F2 compost (Evergreen Garden Care Ltd.) in pots with a top diameter of $14 \mathrm{~cm}, 9.4 \mathrm{~cm}$ bottom diameter and a height of $12 \mathrm{~cm}$ equating to a pot volume of $1.3 \mathrm{~L}$. These plants were used for experiments 28 days or less in duration. When plants were grown for 32 days, seven seedlings were planted in pots with an $18 \mathrm{~cm}$ top diameter, 13 $\mathrm{cm}$ bottom diameter, a height of $16.5 \mathrm{~cm}$ and volume of $3.14 \mathrm{~L}$. Plants were grown in controlled environment chambers at 21 ?, $14 \mathrm{~h} / 10$ day/night regime, $70 \%$ humidity and either at ambient $\mathrm{CO}_{2}$ or $750 \pm 50 \mathrm{ppm} \mathrm{CO}_{2}$ in a Microclima growth cabinet (Snijders Labs). Plant height and branching were determined at day 7, 14 and 32 after transplanting. Height was determined by measuring the stem from the soil to the apical shoot. Total branching was calculated as the sum of the height and length of each branch, not including branches shorter than $5 \mathrm{~mm}$. Fresh and dry plant weight was determined at 28 days after transplanting, while dry weight was determined at 32 days.

\section{Aphid fecundity}

Wild type as well as rms3-1 and rms4-1 pea mutants were germinated and transplanted in the same media and growth conditions as described above. In order to obtain $A$. pisum nymphs of the same age, adult $A$. pisum was placed on WT pea for $24 \mathrm{~h}$ and allowed to produce nymphs. One of these nymphs were then placed a 5-day old plant from each of the genotypes, directly after transplantation. The aphids were contained on the pea plants using 07ZL flowerpot cages (Insectopia), for 15 days while the aphids were allowed to reproduce (Figure 7). Ten replicates were performed for each pea genotype at either ambient or elevated $\mathrm{CO}_{2}$. The number of aphids present on each plant was then determined.

\section{Phytohormone levels}

Entire plant shoots (comprising leaves, stipules and stems) that were fed on by A. pisum were harvested and metabolism was immediately stopped by immersion in liquid nitrogen. Samples were stored at $-80^{\circ} \mathrm{C}$ before freeze drying. Five replicates per line (wild type, rms3-1 and rms4-1 mutant pea) were analysed for cytokinins (trans -zeatin, $\mathrm{tZ}$, zeatin riboside, $\mathrm{ZR}$, and isopentenyl adenine, $\mathrm{iP}$ ), gibberellins $\left(\mathrm{GA}_{1}, \mathrm{GA}_{3}\right.$ \{ gibberellic acid\}, and $\mathrm{GA}_{4}$ ), indole-3-acetic acid (IAA), abscisic acid (ABA), salicylic acid (SA), jasmonic acid (JA), and the ethylene precursor 1-aminocyclopropane-1-carboxylic aid (ACC) according to Albaceteet al. (2008) with some modifications. Freeze-dried tissue $\left(50 \mathrm{mg}\right.$ dry weight, DW) was extracted overnight at $-20^{\circ} \mathrm{C}$ using a methanol/water/formic acid solution (15/4/1 by volume, $\mathrm{pH} 2.5)$. Then, $10 \mu \mathrm{L}$ of internal standard mix, comprising deuterated phytohormones $\left(\left[{ }^{2} \mathrm{H}_{5}\right] \mathrm{tZ},\left[{ }^{2} \mathrm{H}_{5}\right] \mathrm{tZR},\left[{ }^{2} \mathrm{H}_{6}\right] \mathrm{iP},\left[{ }^{2} \mathrm{H}_{2}\right] \mathrm{GA}_{1},\left[{ }^{2} \mathrm{H}_{2}\right] \mathrm{GA}_{3},\left[{ }^{2} \mathrm{H}_{2}\right] \mathrm{GA}_{4}\right.$, $\left[{ }^{2} \mathrm{H}_{5}\right] \mathrm{IAA},\left[{ }^{2} \mathrm{H}_{6}\right] \mathrm{ABA},\left[{ }^{2} \mathrm{H}_{4}\right] \mathrm{SA},\left[{ }^{2} \mathrm{H}_{6}\right] \mathrm{JA},\left[{ }^{2} \mathrm{H}_{4}\right] \mathrm{ACC}$, Olchemim Ltd, Olomouc, Czech Republic) each at 1 $\mu \mathrm{g} \cdot \mathrm{mL}^{-1}$, was added to the extraction homogenate. Solids were then separated by centrifugation $(20,000 \mathrm{~g})$ for $15 \mathrm{mins}$, and extracted again for $30 \mathrm{mins}$ at $4 \mathrm{deg} \mathrm{C}$ in an additional $0.5 \mathrm{~mL}$ of the same extraction solution. The pooled supernatants were filtered through a Sep-Pak Plus C18 cartridge (SepPak Plus, Waters, USA) to remove interfering lipids and plant pigments, and evaporated at $40 \mathrm{oC}$ under a vacuum either to near dryness or until organic solvent was removed. Any remaining residue was dissolved in $1 \mathrm{~mL}$ methanol/water (20/80, $\mathrm{v} / \mathrm{v}$ ) in an ultrasonic bath. The dissolved samples were filtered through $13 \mathrm{~mm}$ diameter Millex filters with $0.22 \mu \mathrm{m}$ pore diameter nylon membrane (Millipore, Bedford, MA, USA). 
Ten $\mu \mathrm{L}$ of filtered extract were injected into a U-HPLC-MS system comprising an Accela Series U-HPLC (ThermoFisher Scientific, Waltham, MA, USA) coupled to an Exactive mass spectrometer (ThermoFisher Scientific, Waltham, MA, USA) using a heated electrospray ionisation (HESI) interface. Xcalibur software version 2.2 (ThermoFisher Scientific, Waltham, MA, USA) was used to obtain mass spectra. To quantify the plant hormones, calibration curves were constructed for each analysed component $(1,10,50$, and 100 $\left.\mu \mathrm{g} \cdot \mathrm{L}^{-1}\right)$ and corrected for $10 \mu \mathrm{g} \cdot \mathrm{L}^{-1}$ deuterated internal standards. Recovery percentages ranged between 90 and $95 \%$.

\section{Statistical analysis}

All datasets to be analysed were firstly subjected to a D'Agostino-Pearson normality test for a Gaussian distribution as well as Spearman's test to determine if variances between variables are heteroscedastic. A two-way ANOVA was performed on datasets conforming to a Gaussian distribution and which were homoscedastic. If an independent variable ( $\left[\mathrm{CO}_{2}\right]$ or genotype) had a significant effect on the response $(\mathrm{P}$ [?] 0.05), Tukey's multiple comparison test was used to compare means. Datasets which were normally distributed, but heteroscedastic were analysed with a Welch ANOVA test followed by Dunnett's T3 multiple comparisons test. Datasets which did not follow a normal distribution were subjected to a Kruskal-Wallis test. Following a significant p-value computed by the Kruskal-Wallis test, multiple comparisons were performed using Dunn's procedure. Different letters indicate a statistically significant difference, p [?] 0.05. Graphpad Prism 8.2.1 was used to perform all statistical analysis.

\section{Results}

The shoot phenotypes of the SL synthesis mutants, rms1-2 andrms5-3, and the SL signalling mutants, rms31 andrms4-1 were monitored for 32 days after germination. The SL mutant shoots were visibly similar to wild type after 7 days of growth (Figure 1). The shoot height was similar in all lines but therms4-1 mutants were significantly more branched than the wild type under both $\mathrm{CO}_{2}$ conditions $(\mathrm{P}=0.0002$; Figure 2$)$. After 14 days (Figure 3), the mutants were significantly shorter and were significantly more branched than the wild type but there were no significant differences arising from growth $\left[\mathrm{CO}_{2}\right]$. Since there were no significant genotype $\mathrm{X}$ environment interactions, all genotypes responded similarly to $\mathrm{eCO}_{2}$.

After 28 days, elevated atmospheric $\left[\mathrm{CO}_{2}\right]$ significantly increased shoot fresh and dry weight $(\mathrm{P}=0.0177$ and $\mathrm{P}=0.0111$ respectively) by $21 \%$ and $23 \%$ respectively. However, there were no significant genotypic differences in fresh or dry weight between the lines (Figure $4 \mathrm{~A}, \mathrm{~B}$ ). Elevated atmospheric $\left[\mathrm{CO}_{2}\right]$ significantly decreased the fresh to dry weight ratio in wild type plants compared to those grown in air $(\mathrm{P}=0.0212)$, but had no effect in any of the SL mutants (Figure $4 \mathrm{C}$ ). However, the fresh to dry weight ratio of the SL mutants was significantly higher than the WT plants.

At this time point, the SL synthesis mutants were visibly more branched than the wild type (Figure 5). Growth under high $\mathrm{CO}_{2}$ for 32 days increased stem height $(\mathrm{P}<0.0001$; Figure $6 \mathrm{~A})$ and shoot branching $(\mathrm{P}=0.0044$; Figure $6 \mathrm{~B})$ similarly in all of the lines. However, the shoots of the wild type peas were $68 \%$ taller with a $65 \%$ reduction in total branching compared to all of the SL mutants under both ambient and high $\mathrm{CO}_{2}$ conditions. The shoot dry weights were significantly higher in all the lines grown under high $\left[\mathrm{CO}_{2}\right]$ compared to those grown in air for 32 days $(\mathrm{P}<0.0001$; Figure 7$)$. However, all of the genotypes showed a similar $\mathrm{CO}_{2}$-dependent increase in shoot dry weight (Figure 7). Thus elevated $\left[\mathrm{CO}_{2}\right]$ effects on stem extension and branching were independent of SLs.

Although growth under high $\mathrm{CO}_{2}$ had no effect on aphid fecundity, there were significantly more aphids on the SL mutants (rms3-1 and rms4-1 grouped) than the wild type pea plants under both $\mathrm{CO}_{2}$ conditions $(\mathrm{P}=0.0286$; Figure 8$)$. Phytohormone levels were determined in aphid-infested shoots grown under either ambient or elevated $\left[\mathrm{CO}_{2}\right]$. Relatively few $\left[\mathrm{CO}_{2}\right]$-dependent changes in phytohormone levels were observed. Growth under elevated $\left[\mathrm{CO}_{2}\right]$ tended to increase the JA levels, but this effect was only significant in therms31 plants (Figure 9). In contrast, trans -Zeatin was decreased in the rms3-1 plants compared to the wild type andrms4-1 plants. Growth under elevated $\left[\mathrm{CO}_{2}\right]$ tended to decrease the levels of gibberellic acid in all the lines (Figure 9). A linear regression analysis indicated that $18 \%$ of the variability in aphid fecundity can 
be explained by the differences in gibberellic acid concentrations $(\mathrm{P}=0.0181$; Figure 10).

\section{Discussion}

SLs fulfil critical functions in regulating plant growth and development, but the roles of these hormones in plant/insect interactions and their responses to changing atmospheric $\left[\mathrm{CO}_{2}\right]$ had not been characterised. The data presented here show that growth under high $(750+-50 \mathrm{ppm}) \mathrm{CO}_{2}$ significantly increases shoot height, biomass accumulation and branching in all genotypes. While all lines showed increased dry matter accumulation (by $40 \%$ when measured 32 days after germination), elevated $\left[\mathrm{CO}_{2}\right]$ significantly decreased shoot water content of wild type but not the SL mutants. This finding is surprising since $A$. thaliana SL mutants had higher stomatal conductance than wild type plants, and their stomatal responses to high $\mathrm{CO}_{2}$ were impaired (Kalliola et al., 2020). Moreover, such mutants have increased sensitivity to drought stress (Ha et al ., 2014). Substantial crosstalk between cytokinins (CKs) and SL signalling pathways in plant drought acclimation has been proposed, with CKs and SLs acting as negative and positive regulators of plant drought responses respectively (Li et al., 2019).

Although SL-deficient plants are often drought-sensitive due to their constitutively higher stomatal conductance (Arabidopsis - Ha et al. 2014; tomato - Visentin et al. 2016) and relative stomatal insensitivity to ABA (Arabidopsis - Ha et al. 2014), the rms pea mutants maintain normal stomatal conductance under optimal conditions (Dodd et al. 2008; Cooper et al. 2018). Impaired stomatal responses to high $\mathrm{CO}_{2}$ in SL-signalling and -biosynthesis Arabidopsis mutants (Kalliola et al., 2020) may have compromised stomatal regulation of plant water relations, but paradoxically the rms lines maintained shoot FW/DW ratio under elevated CO2 here unlike WT plants (Fig. 4C). Since this ratio indicates plant succulence (Mantovani 1999), the high proportion of plant biomass incorporated as young, succulent branching shoots in the rms lines probably accounts for this divergent phenotype under elevated $\mathrm{CO}_{2}$. Even though lignification of plant tissues (which would decrease FW/DW ratio) has not been investigated in SL mutants, impacts of elevated $\mathrm{CO}_{2}$ on xylem anatomy (Liu et al. 2019) and lignification (Richet et al. 2012), may involve SLs, especially since at least some SL-signalling mutants show diminished xylem development (Dodd et al. 2008).

Shoot branching is regulated by CK, SL and auxin crosstalk in axillary buds. The data presented here demonstrate the negative effect of SL on pea axillary bud outgrowth i.e. branching under both ambient and high $\mathrm{CO}_{2}$ conditions. In peas, regulation of SL and CKs converge on the BRANCHED1 (BRC1) transcription factor, which represses bud outgrowth, independent of auxin signals (Brewer et al., 2015). Long-distance transport of SL occurs in the xylem sap (Kohlen et al., 2011), with regulation of SL loading and unloading that regulates bud suppression apparently occurring very close to buds. SLs regulate rice shoot architecture through enhanced cytokinin catabolism (Duan et al., 2020). SL modulates the expression of the OsCKX9 gene, which encodes a CK oxidase, in the regulation of rice tillering, plant height, and panicle size (Duan et al., 2020). CK such as trans-zeatin also play an important role in plant immunity. The data presented show that the levels of trans-zeatin, which is considered to induce resistance to biotrophic pathogens, were differentially changed in response to high $\left[\mathrm{CO}_{2}\right]$ in the rms3-1 and rms4-1 mutants. While the aphid- infested rms4-1 mutants had similar trans-zeatin levels to the wild type, the rms3-1 mutants had significantly less trans-zeatin under both growth conditions. Therms3-1 mutant is defective in the pea orthologue of the rice D14 SL receptor (de Saint Germain et al ., 2016), and hence may be more receptive to the aphidinduced signalling pathways thanrms4-1 mutants, particularly in air. Hence, SL-dependent activation of CK signalling may be important in the resistance of peas to aphid infestation.

Plant defences against root knot nematodes involves the activation of JA- and ABA-mediated defences, which are suppressed in the absence of SL (Xu et al., 2019). The data presented here show that ABA levels were similar in all the aphid-infested lines. Moreover, JA levels were significantly increased by high $\left[\mathrm{CO}_{2}\right]$ in the wild type and rms3-1 mutants. However, high $\left[\mathrm{CO}_{2}\right]$ had no significant effect on aphid fecundity in any of the lines, suggesting that these changes in JA levels were not important in aphid resistance. In contrast, the levels of gibberellic acid were lower at high $\left[\mathrm{CO}_{2}\right]$ in all lines. Moreover, gibberellic acid levels were significantly lower in the rms4-1 mutants, than the wild type peas under both growth conditions. These data not only show that gibberellic acid levels are decreased in the aphid-infested SL mutants. Cross talk between SL 
and gibberellic acid signalling has been reported in the responses of rice plants to Striga infection (Ito et al., 2017). Gibberellic acid was shown to be a regulator of the expression of rice SL biosynthesis genes, while gibberellic acid -treated rice showed reduced Striga infection (Ito et al., 2017). Moreover, the SL receptor, D14, interacts with the gibberellic acid signalling repressor, SLR1 (Nakamura et al., 2013). While there have been very few reports of the role of gibberellic acid in plant/aphid interactions, the levels of this phytohormone were decreased in response to aphids (Wang et al., 2016).

In summary, the data presented here demonstrates that growth under high $\mathrm{CO}_{2}$ does not alter the fecundity of the pea aphid infesting pea plants grown with a full nitrogen supply. Growth under $\mathrm{eCO}_{2}$ decreased the levels of SA and increased JA levels in the wild type peas, without any significant effect on aphid fecundity. However, the absence of SL-mediated defences led to a significant increase in aphid fecundity. This analysis also linked aphid performance to the levels of gibberellic acid in the infested plants. Taken together, these data support the view that plants perceive high $\mathrm{CO}_{2}$ as a stress, as evidenced by changes in phytohormones (Foyer and Noctor, 2020). How far $\mathrm{eCO}_{2}$ stress impacts on plant insect interactions is variable but it likely to depend on other environmental factors as well as the species involved e.g. generalist feeders verses specialists.

\section{ACKNOWLEDGEMENTS}

We thank Dr Alfonso Albacete and Ms. Maria del Puerto Sanchez-Iglesias for their technical support on hormonal analysis, and N8 Agrifood for funds to foster the collaboration between I Dodd and CH Foyer.

\section{Author contributions}

Hendrik Swiegers, Barbara Karpinska and Yan Hu undertook all the experimental work. Hendrik Swiegers analysed all the data and prepared the figures for the manuscript. Ian Dodd oversaw the studies on phytohormones and helped to prepare the manuscript. Anna-Maria Botha co-supervised Hendrik Swiegers, discussed the data and helped to prepare the manuscript. Christine Foyer designed the studies, discussed the data and wrote the manuscript.

\section{References}

Al-Babili S., Bouwmeester H.J. (2015) Strigolactones, a novel carotenoid-derived plant hormone. Annual Review of Plant Biology66: 161-18

Albacete A., Ghanem M.E., Martinez-Andujar C., Acosta M., Sanchez-Bravo J., Martinez V., Lutts S., Dodd I.C., Perez-Alfocea F. (2008) Hormonal changes in relation to biomass partitioning and shoot growth impairment in salinised tomato (Solanum lycopersicum L.) plants. Journal of Experimental Botany 59: 41194131.

Aliche E.B., Screpanti C., De Mesmaeker A., Munnik T., Bouwmeester H.J. (2020) Science and application of strigolactones. New Phytologist227: 1001-1011

Beerling D.J., Kantzas E.P., Lomas M.R., Wade P., Eufrasio R.M., Renforth P., Sarkar B., Andrews M.G., James R.H., Pearce C.R. et al. (2020) Potential for large-scale $\mathrm{CO}_{2}$ removal via enhanced rock weathering with croplands Nature 583 : 242-248.

Botha A.-M., Kunert K. J., Maling'a J., Foyer C.H. (2019) Defining biotechnological solutions for insect control in sub-Saharan AfricaFood Energy Security. 00 : e191.

Brewer P.B., Dun E.A., Gui R., Mason M.G., Beveridge C.A. (2015) Strigolactone inhibition of branching independent of polar auxin transport. Plant Physiology 168: 1820-1829.

Dodd I.C., Ferguson B.J., Beveridge C.A. (2008) Apical wilting and petiole xylem vessel diameter of the rms2 branching mutant of pea are shoot controlled and independent of a long-distance signal regulating branching. Plant and Cell Physiology 49:791-800.

Duan J., Yua H., Yuan K., Liao Z., Meng X., Jing Y., Liu G., Chu J., Lia J. (2019) Strigolactone promotes cytokinin degradation through transcriptional activation of CYTOKININ OXIDASE/ DEHYDROGENASE 
9 in rice. Proceedings of the National Academy of Plant Sciences (USA )116: 14319-14324.

Foyer C.H., Noctor G. (2020) Redox homeostasis and signaling in a higher $\mathrm{CO}_{2}$ world. Annual Review of Plant Biology , 71 :157-182

Foyer C.H., Verrall S.R., Hancock R.D. (2015) Systematic analysis of phloem-feeding insect induced transcriptional reprogramming in Arabidopsis highlights common features and reveals distinct responses to specialist and generalist insects. Journal of Experimental Botany. 66 : 495-512.

Guo H.J., Sun Y.C., Li Y.F., Liu X.H., Wang P.Y., Zhu-Salzman K.. Ge F. (2014) Elevated $\mathrm{CO}_{2}$ alters the feeding behaviour of the pea aphid by modifying the physical and chemical resistance ofMedicago truncatula . Plant Cell and Environment.37, 2158-2168.

Ha C.V., Leyva-Gonzalez M.A., Osakabe Y., Tran U.T., Nishiyama R., Watanabe Y., Tanaka M., Seki M., Yamaguchi S., Van Dong N., Yamaguchi-Shinozaki K., Shinozaki K., Herra-Estrella L., Tran L-S. P. (2014) Positive regulatory role of strigolactone in plant responses to drought and salt stress. Proceedings of the National. Academy of Sciences of the United States of America 111 : 851-856.

Himanen S.J., Nissinen A., Dong W.X., Nerg A.M., Stewart C.N., Poppy G.M., Holopainen J.K. (2008) Interactions of elevated carbon dioxide and temperature with aphid feeding on transgenic oilseed rape: AreBacillus thuringiensis (Bt) plants more susceptible to nontarget herbivores in future climate? Global Change Biology 14 : 1437-1454.

IPCC. (2014) Climate change 2014: synthesis report. R.K. Pachauri, L.A. Meyer (Eds.), Contribution of Working Groups I, II and III to the Fifth Assessment Report of the Intergovernmental Panel on Climate Change [Core Writing Team, IPCC, Geneva, Switzerland: 151.

Ito S., Yamagami D., Umehara M., Hanada A., Yoshida S., Sasaki Y., Yajima S., Kyozuka J., Ueguchi-Tanaka M., Matsuoka M., Shirasu K., Yamaguchi S., Asami T. (2017) Regulation of strigolactone biosynthesis by gibberellin signaling Plant Physiology 174: 1250-1259.

Johnson X., Brcich T., Dun E.A., Goussot M., Haurogne K., Beveridge C.A., Rameau C. (2006) Branching genes are conserved across species. Genes controlling a novel signal in pea are coregulated by other longdistance signals. Plant Physiology 142 : 1014-26.

Kalliola M., Jakobson L., Davidsson P., Pennanen V., Waszczak C., Yarmolinsky D., Zamora O., Palva E.T., Kariola T., Kollist H., Brosche M. (2020) Differential role of MAX2 and strigolactones in pathogen, ozone, and stomatal responses. Plant Direct 4: 1-14.

Kaloshian I., Walling L.L. (2016) Hemipteran and dipteran pests: Effectors and plant host immune regulators. Journal of Integrated Plant Biology 58: 350-361.

Kerchev P.I., Karpińska B., Morris J.A., Hussain A., Verrall S.R., Hedley P.E., Fenton B., Foyer C.H., Hancock R.D. (2013) Vitamin C and the abscisic acid-insensitive 4 (ABI4) transcription factor are important determinants of aphid resistance in Arabidopsis.Antioxidants and Redox Signaling 18 : 2091-2105.

Kiani M., Szczepaniec A. (2018) Effects of sugarcane aphid herbivory on transcriptional responses of resistant and susceptible sorghum.BMC Genomics. 19: 774 .

Koch K.G., Palmer N., Donze T., Scully E.D., Seravalli J., Amundsen K., Twigg P., Louis J., Bradshaw J.D., Heng-Moss T.-M., Sarath G. (2020) Aphid-responsive defence networks in hybrid switchgrass. Frontiers in Plant Science. In press

Li W., Herrera-Estrella L., Tran L-S. P. (2019) Do cytokinins and striglactones crosstalk during drought adaptation? Trends in Plant Science 24: 669-672.

Liu J., Kang S., Davies W.J., Ding R. (2019) Elevated $\left[\mathrm{CO}_{2}\right]$ alleviates the impacts of water deficit on xylem anatomy and hydraulic properties of maize stems. Plant Cell and Environment 43 :563-578. 
Machin D.C., Bennett T. (2020) Two routes to germinate a seed.Nature Plants 6 : 602-603

Mantovani A. (1999) An improved method to improve leaf succulence quantification. Brazilian Archives of Biology and Technology 42, 9-14.

Martinelli F., Scalenghe R., Davino S., Panno S., Scuderi G., Ruisi .P, Villa P., Stroppiana D., Boschetti M., Goulart L.R., et al. (2015) Advanced methods of plant disease detection. A review. Agronomy for Sustainable Development 35 : 1-25.

Marzec M. (2016) Strigolactones as part of the plant defence system. Trends Plant Sciences. 16 : 3012130122 .

Mhamdi A., Noctor G. (2016) High $\mathrm{CO}_{2}$ primes plant biotic stress defences through 1 redox-linked pathways. Plant Physiology 172: 929-942.

Mondor E.B., Tremblay M.N., Awmack C.S., Lindroth R.L. (2005) Altered genotypic and phenotypic frequencies of aphid populations under enriched $\mathrm{CO}_{2}$ and $\mathrm{O}_{3}$ atmospheres. Global Change Biology 11 : 19901996.

Nakamura H., Xue Y.L., Miyakawa T., Hou F., Qin H.M., Fukui K., Shi X., Ito E., Ito S., Park S.H. et al. (2013) Molecular mechanism of strigolactone perception by DWARF14. Nature Communications4: 2613

Nguyen D., Rieu I., Mariani C., van Dam N.M. (2016) How plants handle multiple stresses: hormonal interactions underlying responses to abiotic stress and insect herbivory. Plant Molecular Biology.91: 727740.

Richet N., Afif D., Tozo K., Pollet B., Maillard P., Huber F., Priault P., Banvoy J., Gross P., Dizengremel P., Lapierre C., Perré P., Cabané M. (2012) Elevated $\mathrm{CO}_{2}$ and/or ozone modify lignification in the wood of poplars (Populus tremula x alba ).Journal of Experimental Botany 63 : 4291-4301.

Ryalls J.M.W., Moore B.D., Riegler M., Bromfield L.M., Hall A.A.G., Johnson S.N. (2017) Climate and atmospheric change impacts on sap-feeding herbivores: a mechanistic explanation based on functional groups of primary metabolites. Functional Ecology. 31, 161-171.

Sanchez-Arcos C., Kai M., Svatos A., Gershenzon J., Kunert G. (2019) Untargeted metabolomics approach reveals differences in host plant chemistry before and after infestation with different pea aphid host races. Frontiers in Plant Sciences 10: 188.

Stes E., Depuydt S., De Keyser A., Matthys C., Audenaert K., Yoneyama, K. (2015.) Strigolactones as an auxiliary hormonal defence mechanism against leafy gall syndrome in Arabidopsis thaliana .Journal of Experimental Botany 66: 5123-5134.

Sun Y., Ge F. (2011) How do aphids respond to elevated CO2? Journal of Asia-Pacific Entomology. 14: 217-220.

Smith C.M., Chuang W.P. (2014) Plant resistance to aphid feeding: behavioral, physiological, genetic and molecular cues regulate aphid host selection and feeding. Pest Management Science . 70:528-540.

Torres-Vera R., García J.M., Pozo M.J., López-Ráez J.A. (2014) Do strigolactones contribute to plant defence? Molecular Plant Pathology 15 : 211-216.

Wang H., Liu J., Cui K., Chen H., Yang Z., Wu H., Shao S., King-Jones K., Chen K. (2016) Gibberellic acid is selectively downregulated in response to aphid-induced gall formation. Acta PhysiologiaPlantarum 38: 214

Waters M.T., Gutjahr C., Bennett T., Nelson D.C. (2017) Strigolactone signaling and evolution. Annual Review of Plant Biology 68 : 291-322. 
Xu X., Fang P., Zhang H., Chi C., Song L., Xia X., Shi K., Zhou Y., Zhou J., Yu J. (2019) Strigolactones positively regulate defense against root-knot nematodes in tomato. Journal of Experimental Botany .70: $1325-1337$.

Zust T., Agrawal A.A. (2016) Mechanisms and evolution of plant resistance to aphids. Nature Plants . 2: 15206.

\section{FIGURE LEGENDS}

Figure 1: The effect of high $\mathrm{CO}_{2}$ on the growth of wild type peas and mutants defective either in strigolactone (SL) synthesis (rms1 -2, rms5-3) or signalling (rms3 -1 and rms4-1) for 7 days either under ambient (400 ppm $\mathrm{CO}_{2}$; top row) or high (750 ppm $\mathrm{CO}_{2}$; bottom row).

Figure 2: The effect of high $\mathrm{CO}_{2}$ on the stem height and branching of the shoots of wild type peas and mutants defective either in strigolactone (SL) synthesis (rms1 -2, rms5-3) or signalling (rms3-1 and rms4-1 ) grown for 7 days either under ambient $\left(400 \mathrm{ppm} \mathrm{CO}_{2}\right)$ or high $\left(750 \mathrm{ppm} \mathrm{CO}_{2}\right)$.

Figure 3: The effect of high $\mathrm{CO}_{2}$ on the stem height and branching of the shoots of wild type peas and mutants defective either in strigolactone (SL) synthesis (rms1 -2, rms5-3) or signalling (rms3-1 and rms4-1 ) grown for 14 days either under ambient (400 ppm $\left.\mathrm{CO}_{2}\right)$ or high $\left(750 \mathrm{ppm} \mathrm{CO}_{2}\right)$.

Figure 4: The effect of high $\mathrm{CO}_{2}$ on the fresh weight (A), dry weight (B) and plant water content (C) of wild type peas and mutants defective either in strigolactone (SL) synthesis (rms1 -2, rms5-3) or signalling (rms3 -1 and rms4-1 ) grown for 28 days either under ambient (400 ppm $\left.\mathrm{CO}_{2}\right)$ or high $\left(750 \mathrm{ppm} \mathrm{CO}_{2}\right)$.

Figure 5: The effect of high $\mathrm{CO}_{2}$ on the growth of wild type peas and mutants defective either in strigolactone (SL) synthesis (rms1 -2, rms5-3) or signalling (rms3 -1 and rms4-1). Plants were grown for 28 days either under ambient (400 ppm $\mathrm{CO}_{2}$; bottom row) or high (750 ppm $\mathrm{CO}_{2}$; top row).

Figure 6: The effect of high $\mathrm{CO}_{2}$ on stem height (A), shoot branching (B) in wild type peas and mutants defective either in strigolactone (SL) synthesis (rms1 -2, rms5-3) or signalling (rms3-1 and rms4-1) grown for 32 days either under ambient (400 ppm $\mathrm{CO}_{2}$ ) or high (750 ppm $\left.\mathrm{CO}_{2}\right)$.

Figure 7: The effect of high $\mathrm{CO}_{2}$ on the dry weight of wild type peas and mutants defective either in strigolactone (SL) synthesis SL synthesis (rms1 -2, rms5-3) or signalling (rms3 -1 and rms4-1) grown for 32 days either under ambient (400 ppm $\mathrm{CO}_{2}$ ) or high (750 ppm $\mathrm{CO}_{2}$ ).

Figure 8: The effect of high $\mathrm{CO}_{2}$ on aphid fecundity on wild type peas and mutants defective in strigolactone (SL) signalling (rms3 -1 and rms4-1). A single pea aphid nymph was placed on each 5-day old plant. Plants were then grown in air or under high [CO2]. Aphid numbers per plant were determined 15 days later. Ten replicates were performed for each SL mutant and wild type under each [CO2] per experiment.

Figure 9: The effect of high $\mathrm{CO}_{2}$ and of aphid infestation on the phytohormone levels of wild type peas and mutants defective in strigolactone signalling ( $r m s 3-1$ andrms4-1 $)$.

Figure 10: A linear regression analysis of the relationship between the number of aphids on each plant and the gibberellic content of the plant. Of the variability in aphid fecundity, $18 \%$ can be explained by the gibberellic acid concentrations measured $(\mathrm{P}=0.0181)$. 


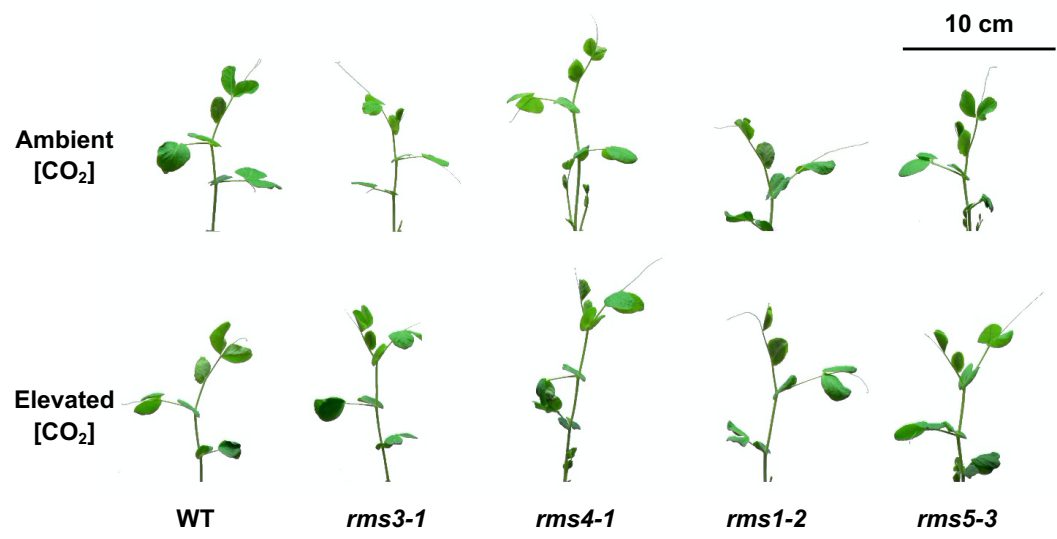



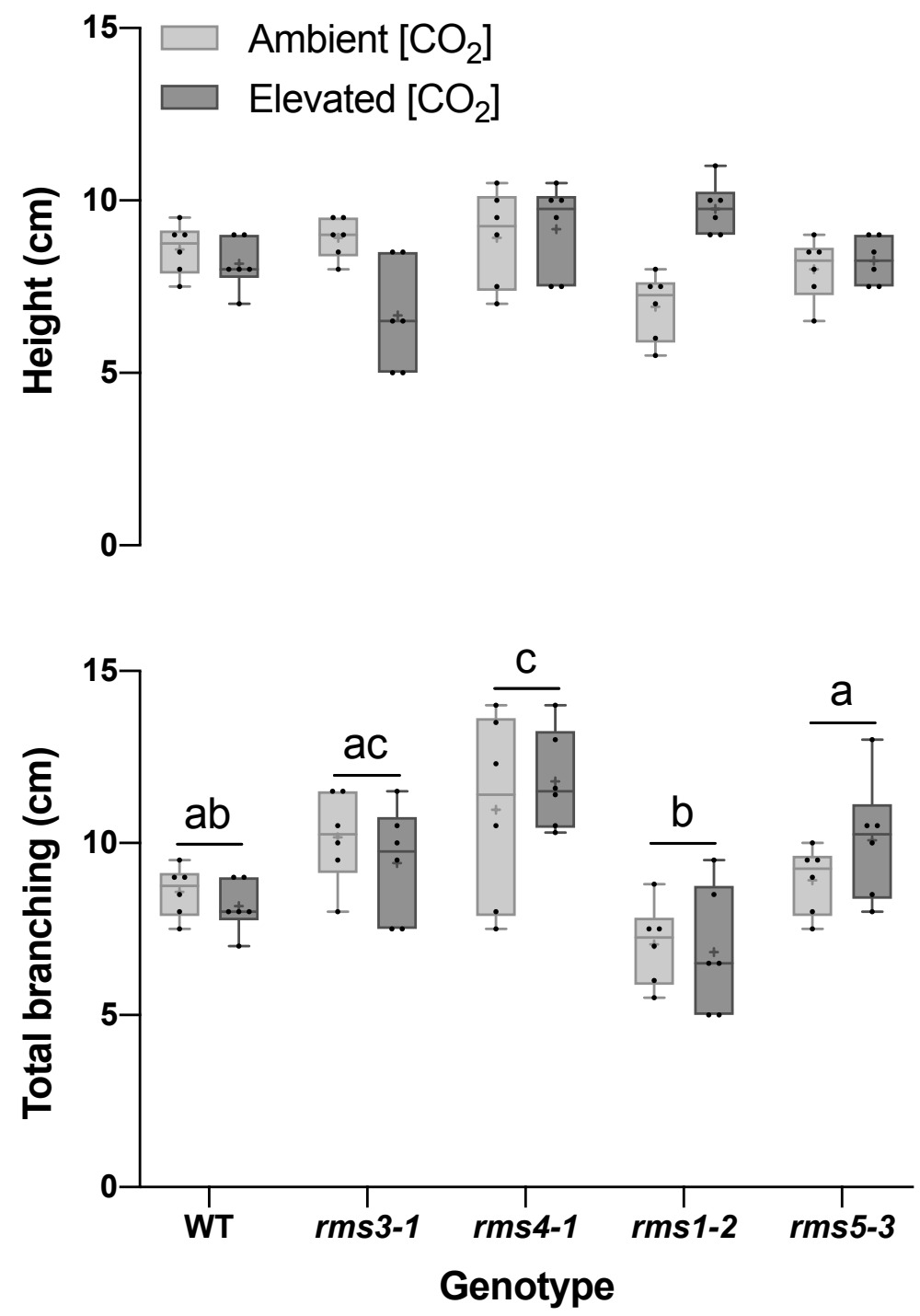


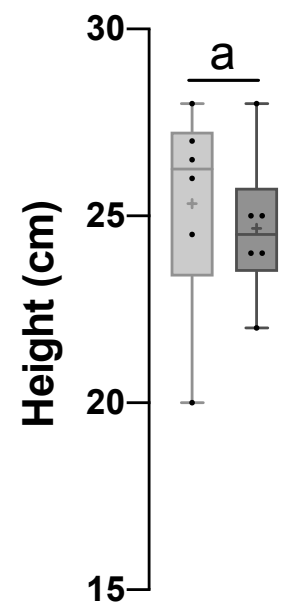

$\square$ Ambient $\left[\mathrm{CO}_{2}\right]$
$\square$ Elevated $\left[\mathrm{CO}_{2}\right]$
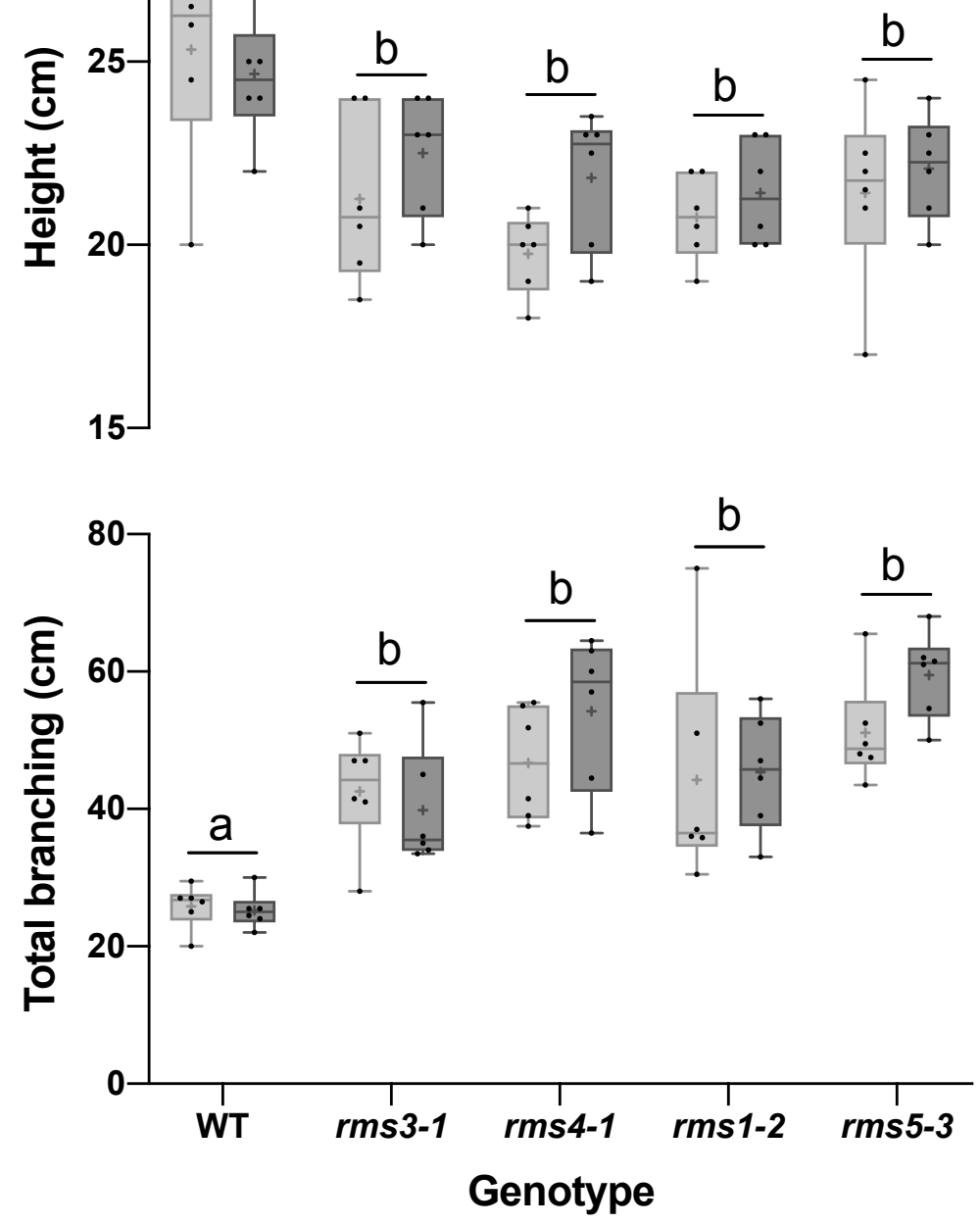


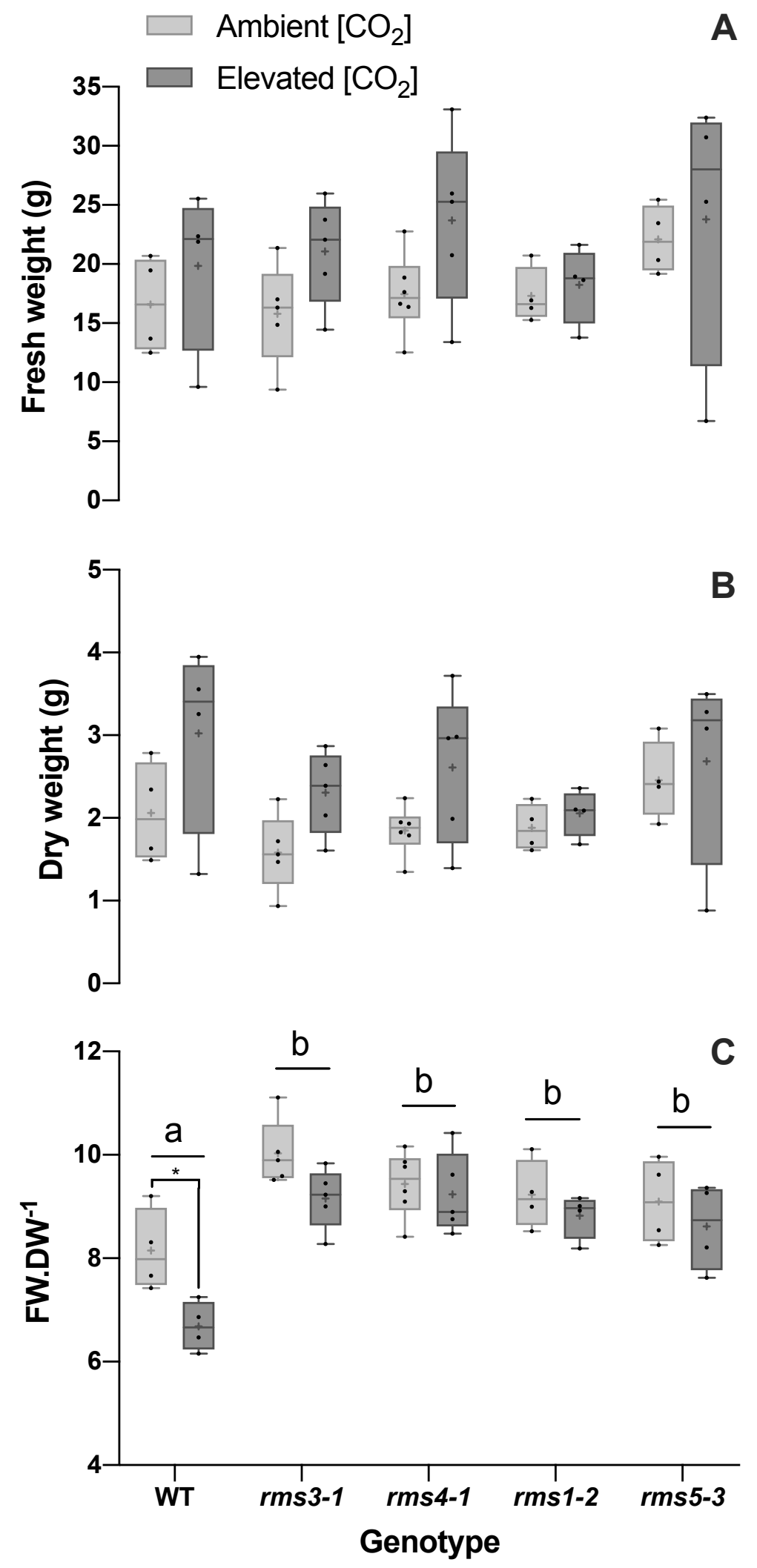




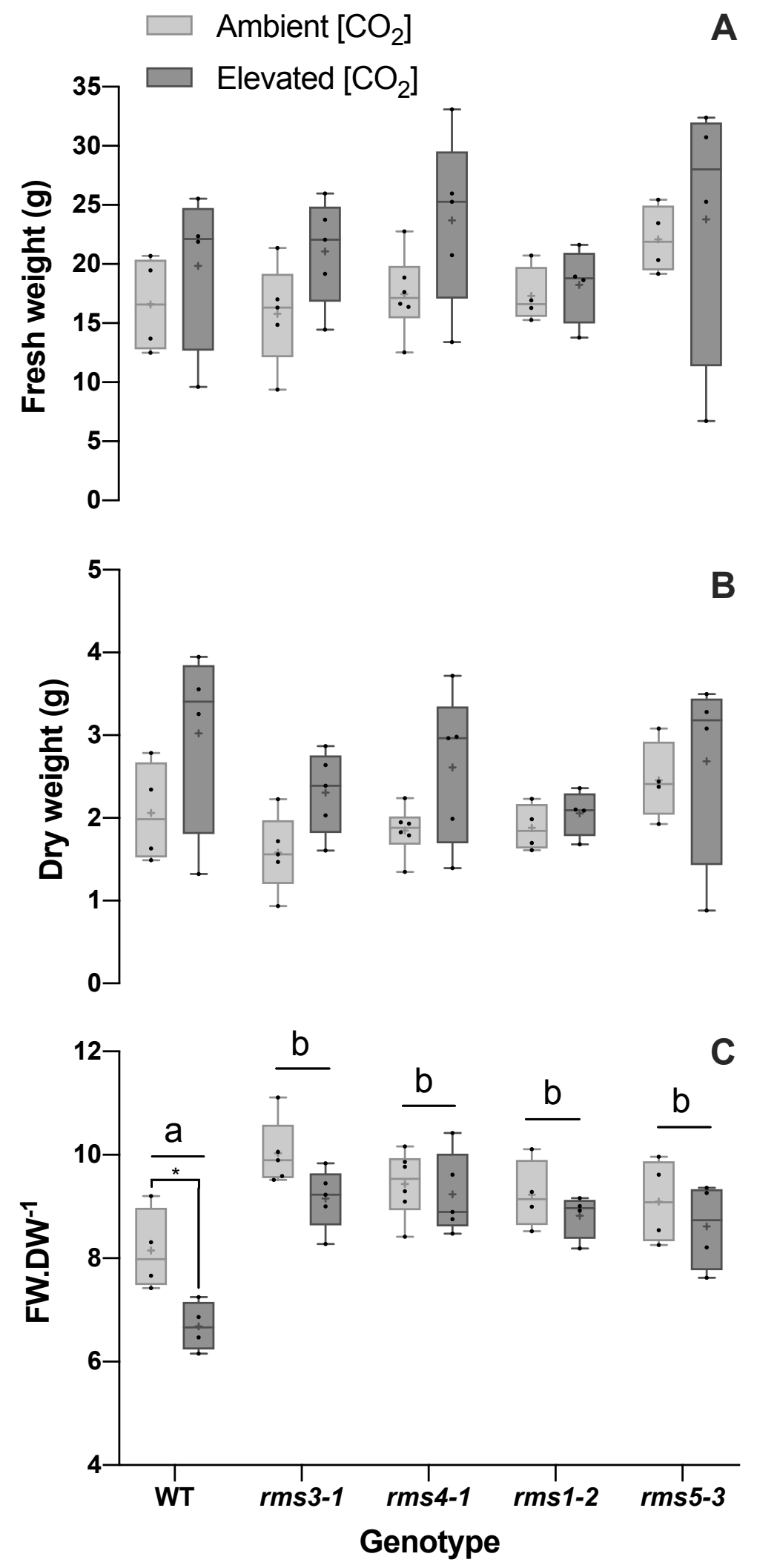




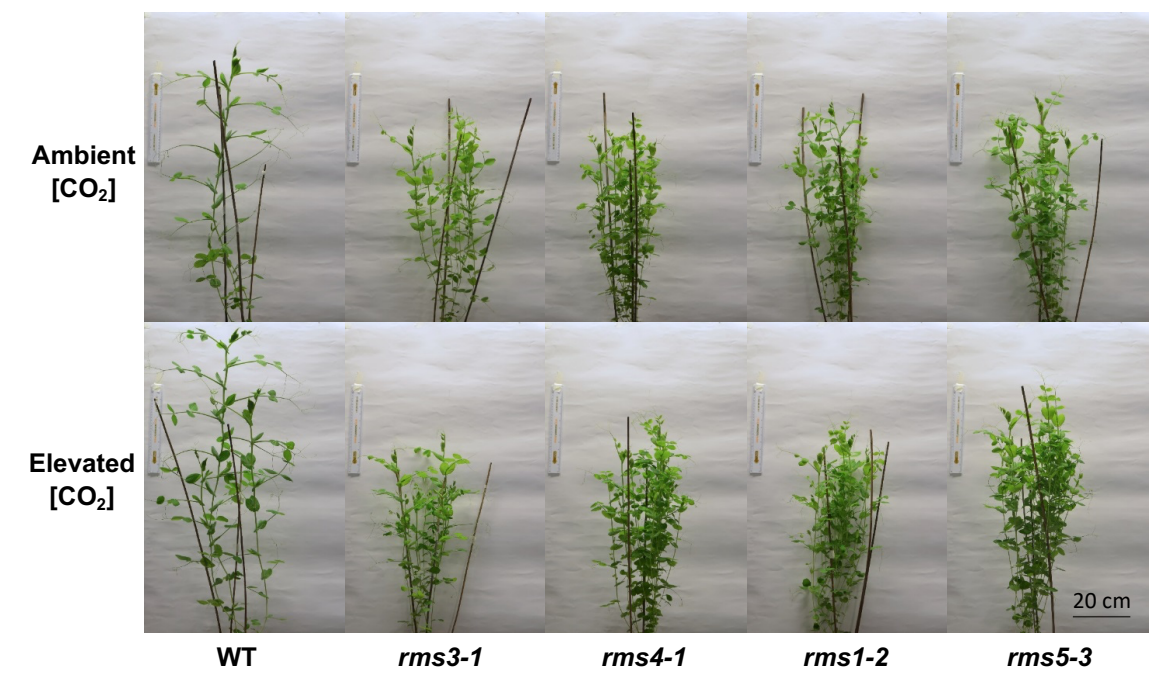



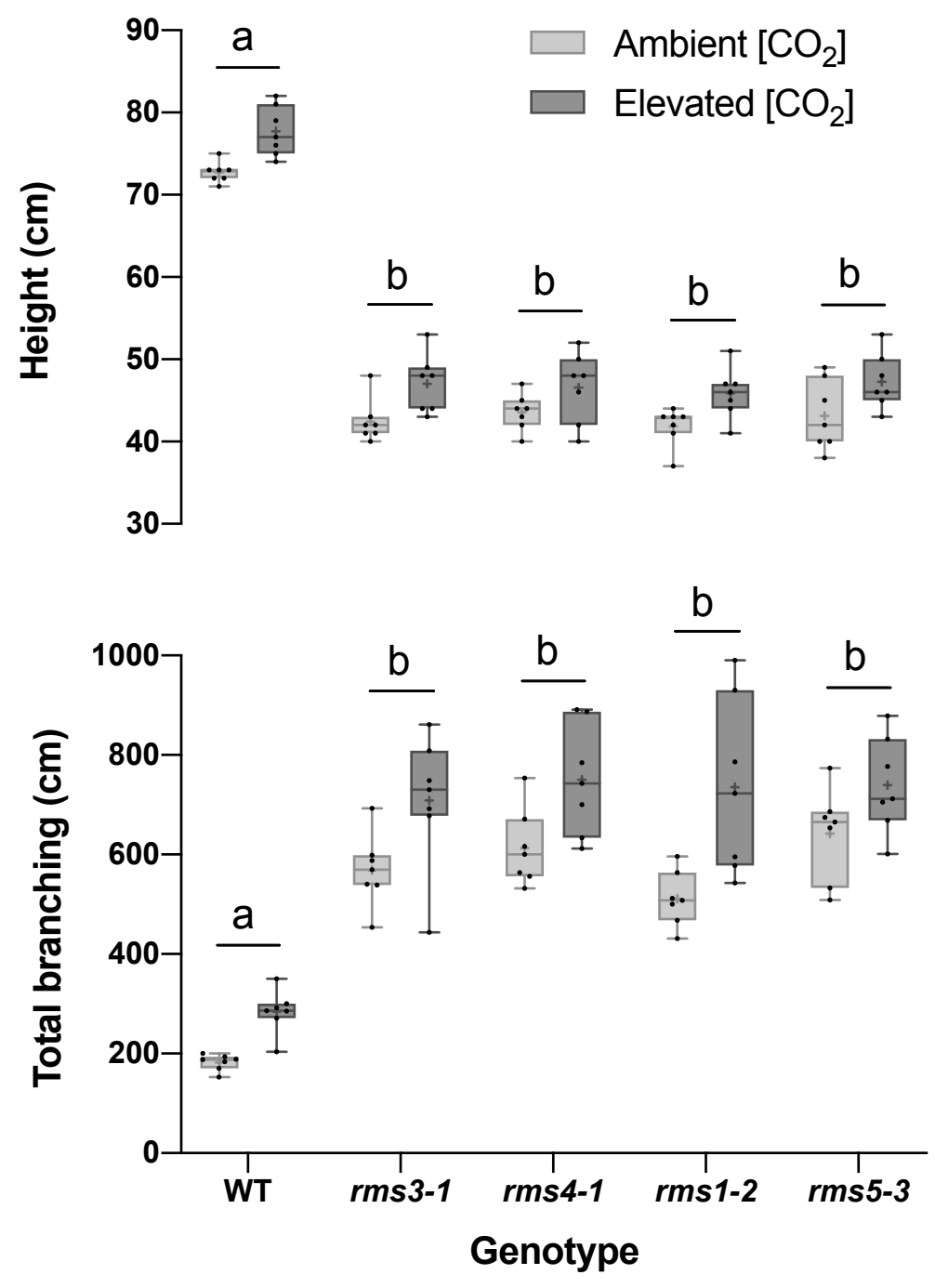


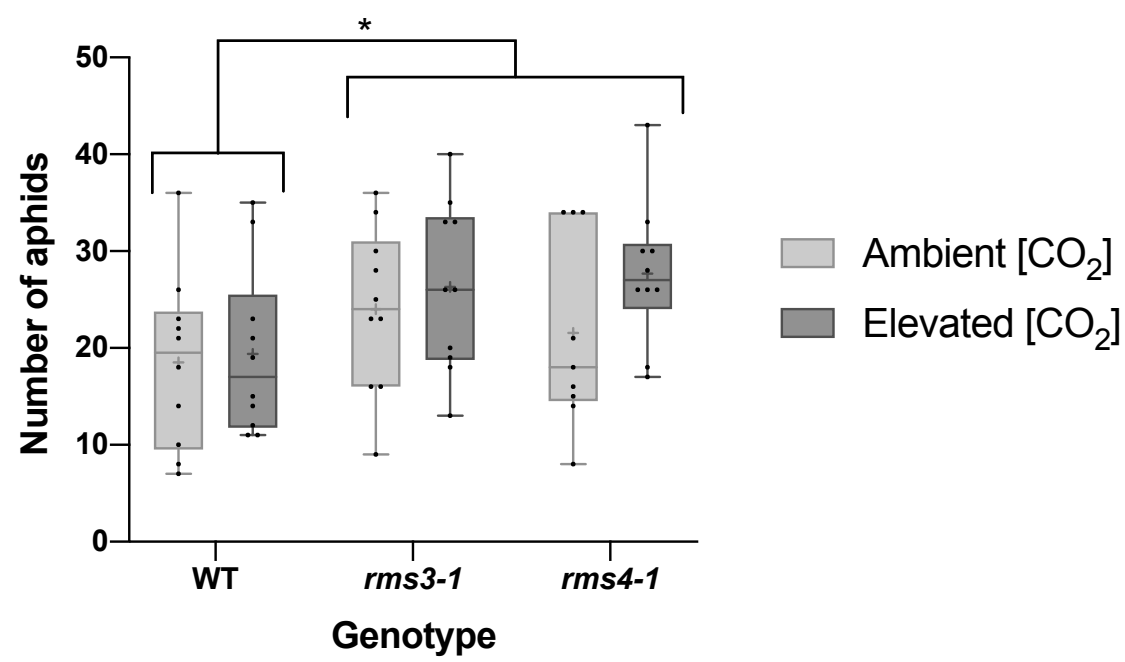




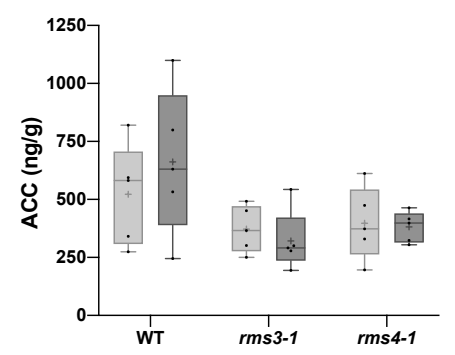

Ambient $\left[\mathrm{CO}_{2}\right]$

$\square$ Elevated $\left[\mathrm{CO}_{2}\right]$
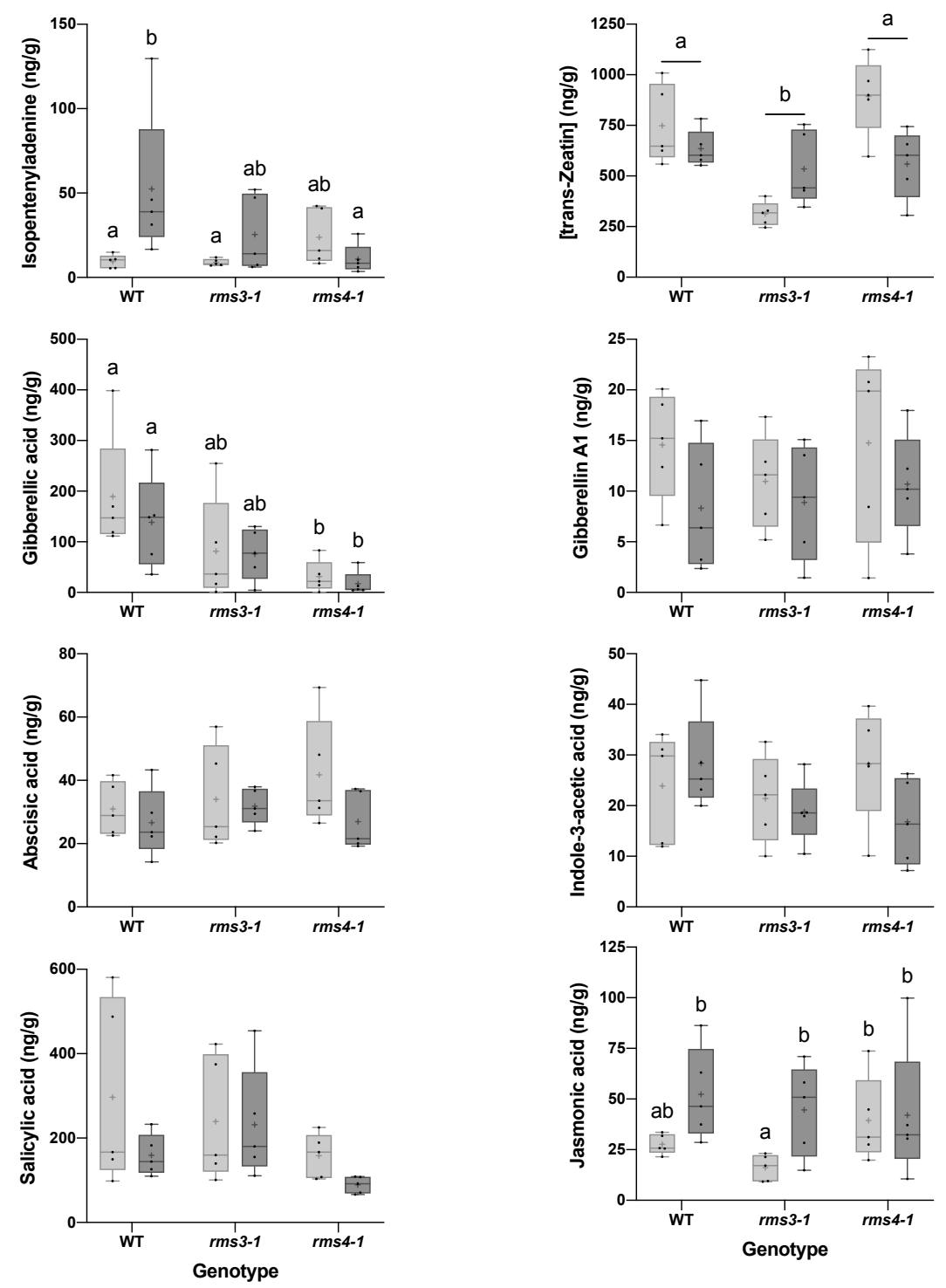


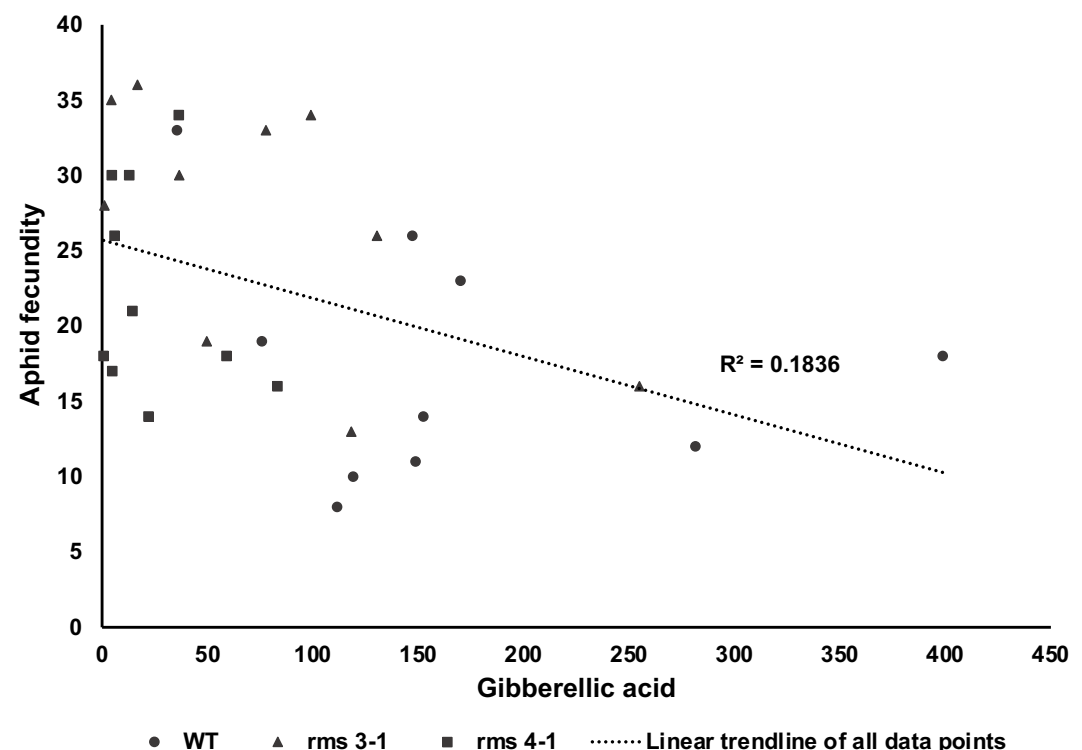

